\title{
Comparative study of microbial inoculants of cultivated and virgin soils of Nilgiri Biosphere for plant growth promotion
}

\author{
P. Raja* and V.P. Santhi ${ }^{1}$ \\ Horticultural Research Station, Tamil Nadu Agricultural University, Udhgamandalam (T.N.) India \\ (Email : rajamicro@gmail.com)
}

\begin{abstract}
In virgin soils, microorganisms and plants live in harmony and both are dependent on each other for their livelihood. Absence of cultivation practices, undisturbed soil condition, high organic matter condition and other favourable conditions enables to flourish beneficial microbes. The research work was started to identify beneficial microbes from undisturbed virgin soils of Nilgiri biosphere with the ability to grow under low $\mathrm{pH}$ and under low temeperature conditions. Bio-inoculants viz., Azospirillum, Phosphobacteria, Azotobacter, Rhizobium and pseudomonas were obtained from cultivated and virgin soil samples of Nilgiris biosphere. When compared with type cultures, virgin soil isolates of respective inoculants have recorded better results in promoting plant dry weight in paper towel method. In cross streak assay, selected isolates found to be compatible with each other. In lignite carrier base formulation, the inoculants have reached a maximum population level of $10^{7}$ and phosphobacteria reached $10^{8}$ level. The population remained steady at this level up to 3 months. In the field trial studies conducted, the treatment of Azospirillum + Azotobacter + Phosphobacteria + Pseudomonas $+75 \%$ RDF has recorded maximum population of all the inoculants at $45^{\text {th }}$ day after sowing. However, the maximum yield was observed in $100 \%$ RDF and bio-inoculant consortium applied treatment. This was closely followed by $75 \% \mathrm{RDF}$ and bio-inoculant consortium applied plots. The results of the field trial have shown that bio-inoculant consortium along with $75 \%$ RDF application will lead to maximum yield with $25 \%$ saving in chemical fertilizer application.
\end{abstract}

Key Words : Bio-inoculants, Virgin soil, Azospirillum, Azotobacter, Phosphobacteria, Pseudomonas, Plant growth promotion

View Point Article : Raja, P. and Santhi, V.P. (2021). Comparative study of microbial inoculants of cultivated and virgin soils of Nilgiri Biosphere for plant growth promotion. Internat. J. agric. Sci., 17 (2) : 293-298 DOI:10.15740/HAS/IJAS/17.2/293-298. Copyright@2021: Hind Agri-Horticultural Society.

Article History : Received : 23.02.2021; Revised : 26.02.2021; Accepted : 15.03 .2021

\footnotetext{
* Author for correspondence :

${ }^{1}$ Horticultural College and Research Institute for Women, Tamil Nadu Agricultural University, Tiruchirapalli (T.N.) India
} 